\title{
MISSION STATEMENT ACCOMPLISHED: PROMISES AND CHALLENGES IN USING E-PARTICIPATION FOR MISSION STATEMENT DEVELOPMENT
}

\author{
Jonas Fegert, Carolin Stein, Christian Peukert and Christof Weinhardt \\ Karlsruhe Institute of Technology, Institute of Information Systems and Marketing, Kaiserstr. 89-93, \\ 76133 Karlsruhe, Germany
}

\begin{abstract}
Mission statements are written declarations that summarize and communicate an organization's core values and strategies and present managerial tools that can be used to motivate employees by creating a common self-understanding of an organization. With politics aiming to become ever more inclusive and participative ranging from the local to the global level, new technologies and findings about possibilities of self-determined, collaborative work from the field of e-participation emerge, which can be transferred onto organizational participation. We therefore present a procedure for incorporating e-participation approaches in mission statement creation processes to make place for more collaborative and open processes. This paper presents an eight-step nominal group process for the participative online creation of a mission statement. The process was tested and evaluated within three consecutive studies that surrounded different stages of a mission statement development, which relied on an existing e-participation platform. Our core findings show that (1) the participants of this initiative considered the use of e-participation to be helpful for mission statement creation and generally support the proposed process structure, (2) the platform's suitability for developing mission statements was reviewed critically, making suggestions for important criteria of digital mission statement creation tools that should be met, and (3) participants could identify themselves with the final mission statement more strongly because of their own participation in the development process. While observing overall support for the suggested mission statement creation procedure, we build on the results of our studies to make suggestions for the design of e-participation platforms that will make them even more suitable for mission statement development.
\end{abstract}

\section{KEYWORDS}

Mission Statement Development, E-Participation, Digital Government, Participatory Design 


\section{MISSION STATEMENT ACCOMPLISHED: PROMISES AND CHALLENGES IN USING}

E-PARTICIPATION FOR MISSION STATEMENT DEVELOPMENT

\section{INTRODUCTION}

For the purpose of defining shared values, mission statements became a trusted instrument for profit- and non-profit organizations worldwide. They are used as a tool to motivate employees (Klemm et al. 1991), involving them in the strategic management of an organization (Campbell and Yeung 1991), and to create a common understanding among them (King 1978). Since the effectiveness of the mission statement is closely related to its content (Blair-Loy et al. 2011; Sattari et al. 2011), research mainly focuses on textual aspects and elements of the mission statement. However, employees seem to value the development process as equally or even more important than the resulting document (Desmidt and Prinzie 2009). Baetz and Bart (1996) show that employees wish to be involved in the development through active discussions and feedback opportunities and appreciate when the process makes an effort in bringing the team together. Similarly, the organization and the mission statement itself may profit from the discussion of potentially conflicting opinions and ambitions (Baetz and Bart 1996). These findings are also echoed by newer research endeavors highlighting the innovative and transformative power of participatory approaches in organizations (Wagenknecht et al. 2017a; b; c), e.g., using methods like open innovation (Adamczyk et al. 2012).

As social networks create more spaces for political engagement and discussions (Lindner and Aichholzer 2020), people receive more opportunities to get involved politically and voice their opinion online. , The 2030 Agenda for Sustainable Development of the United Nations reacts to this development by aiming to "ensure responsive, inclusive, participatory and representative decision-making at all levels" (United Nations 2015, p. 25). In relation to that, the United Nations (2019) also declare that "online tools can enhance access to information and public services, as well as promote better public policy decision-making" (p. 33). This goes in line with the increase in digital government projects hosted by governmental institutions in the last decades (United Nations 2020b). E-participation, a form of e-government (also known as digital government), established itself as a way of facilitating citizen involvement in "democratic decision-making" (Macintosh 2004, p. 2) by employing information and communication technology (ICT). Cities, municipalities, companies, and research institutions use e-participation to involve stakeholders in certain processes and decisions (Thiel et al. 2018). By that, they often aim at improving the overall acceptance of certain projects. E-participation research proved that the use of new digital technologies could strengthen the interest in projects and increase the motivation to participate (Fegert et al. 2020).

When temporary lockdowns prevent face-to-face interactions - as we have globally observed during the Covid-19 pandemic - involving employees in mission statement development must inevitably be carried out online - as opposed to conventional participatory settings like workshops. In addition to that, it appears plausible that the employees' identification with their team and the organization they work for might decrease, when the workspace shifts into the private sphere, thereby leaving interaction with colleagues behind. In such times, e-participation naturally emerges as a means to facilitate remote collaborative work (United Nations 2020a). One effect of the pandemics is that for many people, remote working increasingly poses itself as a viable option to working in the office (Bonacini et al. 2021). In Germany, politicians called for an introduction of a right to work from home (Deutsche Welle 2020). Furthermore, remote working can pose an option for online conference and meetings, which can help address global carbon emissions (Klöwer et al. 2020; Ekstrom et al. 2020) However, translating long-established 'offline' formats like workshops into online meetings 
requires suitable digital environments that can go beyond regular chat or videocall options. Due to their deliberative character (Sanford and Rose 2007), e-participation platforms promise to introduce an appropriate environment for participatory mission statement development outside of the office, making place for online-consultation and transparent decision-making (Macintosh 2004).

In this paper, we provide insights from a participatory mission statement creation process that was realized with an e-participation platform. We present a process consisting of eight activities for the purpose of mission statement development using e-participation. Furthermore, our use case, a research institute at which 32 full-time employees used an existing e-participation platform to create a fitting mission statement, allows us to outline design guidelines concerning the general design of e-participation platforms for that purpose. Three survey-based evaluations were used to examine users' experience throughout the participation process. Based on the evaluations, we demonstrate promises and challenges that arise from using e-participation for mission statement development. Through designing, implementing, and evaluating a process for the given use case, we intend to derive first insights potentially leading towards a design theory for mission statement development with e-participation platforms.

\section{THEORETICAL FOUNDATION}

\subsection{Mission Statements}

Mission statements are documents summarizing the core values and strategies of an organization (Baetz and Bart 1996). The mission statement is an important factor in the strategic management also due to its visibility and public accessibility (Cochran et al. 2008). Overall, it provides guidance towards the orientation and goals of an organization, bearing the potential to influence its effectiveness (Desmidt and Prinzie 2009). However, the degree to which a positive impact is reached depends on the design, content, and wording of the mission statement (Desmidt and Prinzie 2009). The respective literature suggests that the following aspects should be included in a mission statement: "target customers and markets," "principal products/or services," "specification of geographic domain," "identification of core technologies," "key elements in the companies" philosophy," "identification of the self-concept," and "identification of the [...] desired public image" (Pearce and David 1987, p. 112). With the message often being the center of research, less attention has been paid to the development process of the mission statement. A literature review on mission statement research conducted by Alegre et al. (2018) distinguish different types of mission statement articles, one of them concerning the "definition, creation and implementation" (p. 460) of mission statements. According to Alegre et al. (2018), most of these work emerged in the 1980s and early 1990s - a time when mission statements were commonly developed by top management, offering a draft to their subordinates for subsequent reviewing "until the CEO was satisfied" (Alegre et al. 2018, p. 461). Already then, however, missions statements were observed to be rather top-down and lacking the involvement of various stakeholders (Alegre at al. 2018). At the same time, Alegre et al. (2018) record a decline in high-quality papers dealing with the initiation of a mission statement creation, suggesting a scarcity in more recent research on this topic. Moreover, research has shown that the creation process is valued as more important or equally important as the actual resulting mission 


\section{MISSION STATEMENT ACCOMPLISHED: PROMISES AND CHALLENGES IN USING}

E-PARTICIPATION FOR MISSION STATEMENT DEVELOPMENT

statement (Baetz and Bart 1996) and that the process of developing a commonly accepted message is just as vital as the message itself (Cochran et al. 2008). Baetz and Bart (1996) showed that within processes of mission statement creation, when stakeholders felt isolated and not sufficiently involved, they usually ended up being unsatisfied with the process. Furthermore, collecting input from everyone was often named as a reason for satisfaction. These results indicate that top-down approaches might be outdated for mission statement development and that there is room for improvement. Therefore, we argue that a more participative and inclusive development of a mission statement could solve a few of the mentioned problems.

\subsection{E-Participation}

With the emergence of ICT, e-democracy or digital democracy has evolved as an extension of "classical" democracy and participation theories, conceptualizing normative ideas about democratic societies (Lindner and Aichholzer 2020). E-democracy is a form of e-government, which encompasses technologies that aim at engaging citizens in democratic decision-making (Macintosh 2004) and shall be differentiated from e-administration, which focuses on online public services provision. E-participation, in turn, presents one form of e-democracy, which is defined as the possibility to participate in and influence policy decisions using ICT (Macintosh 2004). Although e-participation makes use of certain ICTs, no single e-participation technology exists (Sanford and Rose 2007). Instead, various online participation platforms and tools implement ICTs and various software solutions in the projects.

Overall, three main models of democracy can be differentiated: the liberal, the republican, and the deliberative model, and they can guide the aims of e-participation respectively (Lindner and Aichholzer 2020). In their literature review on e-participation artifacts, Sanford and Rose (2007) demonstrate that e-participation "research tends to focus on liberal, collaborative forms of participation [...] rather than [...] more direct form[s] of democracy" (Sanford and Rose, 2007, p. 416) like e-voting. As a result, e-participation produces more participation, but not automatically more democracy and has therefore to be differentiated from e-democracy (Grönlund 2009). This explains why e-participation platforms were in their beginning especially popular in non-democratic states, in which e-participation might be used as a token and public relation tool to draw a picture of modernity and democratic participation (Åström et al. 2012).

Besides the use for public participation projects, e-participation has already proven its merits for corporate participation (Niemeyer et al. 2016; Wagenknecht et al. 2017b), where it can support idea creation processes. With its specific orientation towards democratic and socially interactive elements, e-participation and its platforms go beyond classical computer-supported cooperative work (CSCW). While cooperative work generally refers to the elaboration or revision of artifacts through joint interactions between individuals (Grundin 1994), e-participation tends to focus on the exchange of opinions and consensus building. Existing frameworks provide guidance for a successfully execution of e-participation projects (Niemeyer et al. 2016; Scherer and Wimmer 2011). Taking into consideration the many opportunities that e-participation offers for collaborative settings, we want to research the combination of missions statements and e-participation. 


\section{METHODOLOGY AND USE CASE}

Schererer and Wimmer (2011) follow a holistic approach to the design of e-participation projects. They accordingly suggest a reference design framework that consists of the following four phases: initiation and design, preparation, realization, and evaluation (Scherer and Wimmer 2011, p. 7). In the course of this section, each phase should be described by recounting the conducted activities, highlighting related literature, and presenting the respective results. The different phases of this framework will be described after a brief introduction of the use case.

The participatory process will be tested within the development of a mission statement for a technology-oriented institute of a large public European university. The institute is headed by a professor and co-led by a team of six postdoctoral researchers (leadership team), representing different research groups, which consist of several $\mathrm{PhD}$ students as well as graduate student researchers and student research assistants. In total, the research group involves 32 full-time staff members, including administrational staff members. All team members are well experienced with technology usage since it is an Information Systems institute. The project itself was conducted over two and a half months, starting in July 2020 and administered by the authors of this paper.

Initiation and design: The initiation and design phase resulted in finding a suitable structure and platform for the participatory mission statement development process. A framework for an effective development of a mission statement is given by Cochran et al. (2008). Their four-step process includes an orientation phase, a component analysis, a communication analysis, and an applicability analysis. Facing the problem of the absence of shared workspaces due to the Covid-19 pandemic, the institute started rethinking practices and values (Table 1, Activity 1). Once the institute's leadership team decided to work on a mission statement, following Cochran et al. (2008), the major headlines framing the mission statement were decided on, to provide a guideline for the following participatory process. Based on the set of relevant aspects of mission statements by Pearce and David (1987), the leadership team structured the discussion into four topics (Activity 2): students ("target customers and markets," "services," "specification of geographic domain"), leadership ("identification of self-concept"), team ("identification of self-concept," "philosophy"), public relations ("identification of "core technologies' and the 'desired public image" ").

Reflecting the participants' roles is essential for each e-participation project (Kalampokis et al. 2008). It should thus be differentiated between the input provider, the decision makers, the moderator, and the owner of the process. The structure of the institute directly implies a certain role distribution: the process is headed by the professor, implying that strategic process decisions require his approval. The professor is in the position to initialize the process and agree with the institute's team members on the necessary working time required for participation. The moderating role was split among the postdoctoral researchers to profit from their position and influence on their groups. They were expected to motivate the employees and be a point of contact in case of any concerns. Since the goal of the project is a participatory and democratic process, the input and decision roles belong to all team members equally.

Preparation: The preparation phase mainly included the search for a suitable e-participation platform. The choice was based on a requirement analysis made by the institute leadership team, agreeing on the following essential characteristics: facilitating idea collecting, group discussions, and voting mechanisms. Phang and Kankanhalli (2008) present a three-step 


\section{MISSION STATEMENT ACCOMPLISHED: PROMISES AND CHALLENGES IN USING}

E-PARTICIPATION FOR MISSION STATEMENT DEVELOPMENT

procedure to implement e-participation initiatives that identifies the (1) objectives, (2) techniques, and (3) ICT tools which support the techniques and thereby the objectives. Phang and Kankanhalli (2008) suggest a structured participatory technique named "decision-making supplement", which fits the intentions of the project at hand and is defined by a nominal group process. A nominal group process is a step-by-step process in which suggestions are ranked and the outcome of one stage works as a recommendation for the following stage. An ICT tool could, for example, support an idea collection on a predefined topic, which then merges into a discussion of the ideas and underlying concepts to achieve a consensus through a voting mechanism as a final step. We combined those suggestions with some structural ideas on mission statement development made by Cochran et al. (2008; see Table 1).

Based on the described requirements and activities, we decided to use a platform developed by a European startup, which is used by public institutions, political parties, and international organizations. The choice of the platform was finalized in a meeting with the startup's CEO and several staff members, who guided us through the characteristics of their platform. The platform claimed being able to support mission statement development processes, while the suggested participation modules resembles our requirements.

Realization: The e-participation project was conducted over a period of eleven weeks, accompanied by three weeks of offline preparations. The initial platform setup was done by the authors in agreement with the postdoctoral researchers. Participants received an e-mail invitation for the online project, providing the option to create a pseudonymized profile. After logging in to the platform, they were welcomed with an overview screen of the project consisting of a project timeline and the overview of the participation modules. Clicking on the different modules would take them to the respective activity, where clear indications ("Join now") were given to guide the users to the participation opportunities. The realization started with a hybrid offline and online kick-off workshop. In the workshop, which gave an introduction into the e-participation project and the platform, overall, 86 ideas across four categories were collected (Activity 3) and transferred to the platform. For several weeks, this initial idea collection was discussed online (Activity 4). Following an online voting (Activity 5), the postdoctoral researchers created sixteen mission statement alternatives out of the top voted proposals (Activity 6). For each of the four categories, these differed slightly in wording and phrasing. This was followed by another online voting (Activity 7), which resulted in a finalized version of the mission statement with one statement for each category. The last step of the idea collection process consisted of working out actions for operationalizing the mission statement into the daily business of the institute (Activity 8). This step led to 131 initiatives on how the mission statement could be operationalized and used in the future. During the whole participation process, a weekly e-mail newsletter was sent out to the participants to motivate and remind them to stay involved and offering them a point of contact in case of problems. Activity six and seven of this process replace the communication analysis suggested by Cochran et al. (2008) though we believe that the suggested democratic process will bring up the most convenient mission statement out of the alternatives. 
IADIS International Journal on Computer Science and Information Systems

Table 1. Activities, Expected Outcomes of the Nominal Group Process, and Modules

\begin{tabular}{|c|c|c|}
\hline Activity & Expected Outcome & Module \\
\hline 1. Orientation & $\begin{array}{l}\text { Moderators and owners become aware of their } \\
\text { role }\end{array}$ & - \\
\hline 2. Component analysis & $\begin{array}{l}\text { Component categories for the idea collection } \\
\text { are specified }\end{array}$ & - \\
\hline 3. Idea collection & $\begin{array}{l}\text { Ideas concerning the different topics are } \\
\text { collected }\end{array}$ & Debate $^{\text {a) }}$ \\
\hline 4. Discussion of ideas & $\begin{array}{l}\text { General understanding for different ideas is } \\
\text { developed }\end{array}$ & $\begin{array}{l}\text { Prioritization } \\
\text { b) }\end{array}$ \\
\hline 5. Vote on ideas & Ideas are prioritized via up- and downvotes & $\begin{array}{l}\text { Prioritization } \\
\text { b) }\end{array}$ \\
\hline $\begin{array}{l}\text { 6. Formulation of } \\
\text { mission statement }\end{array}$ & $\begin{array}{l}\text { Different textual mission statement alternatives } \\
\text { are } \\
\text { developed by the leadership team }\end{array}$ & - \\
\hline 7. Vote on mission statement & Decision on the mission statement & $\begin{array}{l}\text { Prioritization } \\
\text { b) }\end{array}$ \\
\hline $\begin{array}{l}\text { 8. Idea collection on applicability } \\
\text { and operationalization }\end{array}$ & $\begin{array}{l}\text { List of ideas for specific application of the } \\
\text { mission statement }\end{array}$ & Debate $^{\text {a) }}$ \\
\hline \multicolumn{3}{|c|}{$\begin{array}{l}\text { Techniques used: a) Proposals are condensed to predefined categories; possibility to up- and } \\
\text { downvote or comment proposals; filtering and tagging of proposals; b) Opportunity to comment and } \\
\text { up- or downvote predefined proposals; new proposals cannot be added; other users' comments can be } \\
\text { up- or downvoted. }\end{array}$} \\
\hline
\end{tabular}

Evaluation: The first process evaluation (Evaluation Phase 1) was conducted after Activity 5 and was included as a module in the e-participation process. As the preliminary analysis of the first questionnaire has to some degree already indicated signs of dissatisfaction among the participants, we decided to examine the attitude towards the overall user experience of the platform in an additional non-obligatory questionnaire (Evaluation Phase 2). In doing so, we adapted a theoretical model by Naranjo-Zolotov et al. (2019), which evaluated an e-participation tool relying on the unified theory of acceptance and use of technology (UTAUT) (see Venkatesh et al. 2003), followed by three open questions (Table 2). The final evaluation (Evaluation Phase 3 ) was designed as a follow-up questionnaire, after the participants had settled with the mission statement. To measure the quality of the mission statement and the qualitative influence of the participatory process, we used the theoretical construct "Congruence between values" adapted from the "Questionnaire of personal and organizational values congruence for employee" (Q-POVC), followed by self-developed items. The construct uses abstract phrasings in order to assess how much personal values of an employee match the ones present in an organization (Vveinhardt and Gulbovaite 2015). The evaluation results are presented in the results chapter of this paper. 


\section{MISSION STATEMENT ACCOMPLISHED: PROMISES AND CHALLENGES IN USING E-PARTICIPATION FOR MISSION STATEMENT DEVELOPMENT}

Table 2. The Two Phases of the E-Participation Evaluation. Note: We used seven-point Likert scales ranging from "strongly disagree" to "strongly agree" to measure the theoretical constructs if not stated otherwise

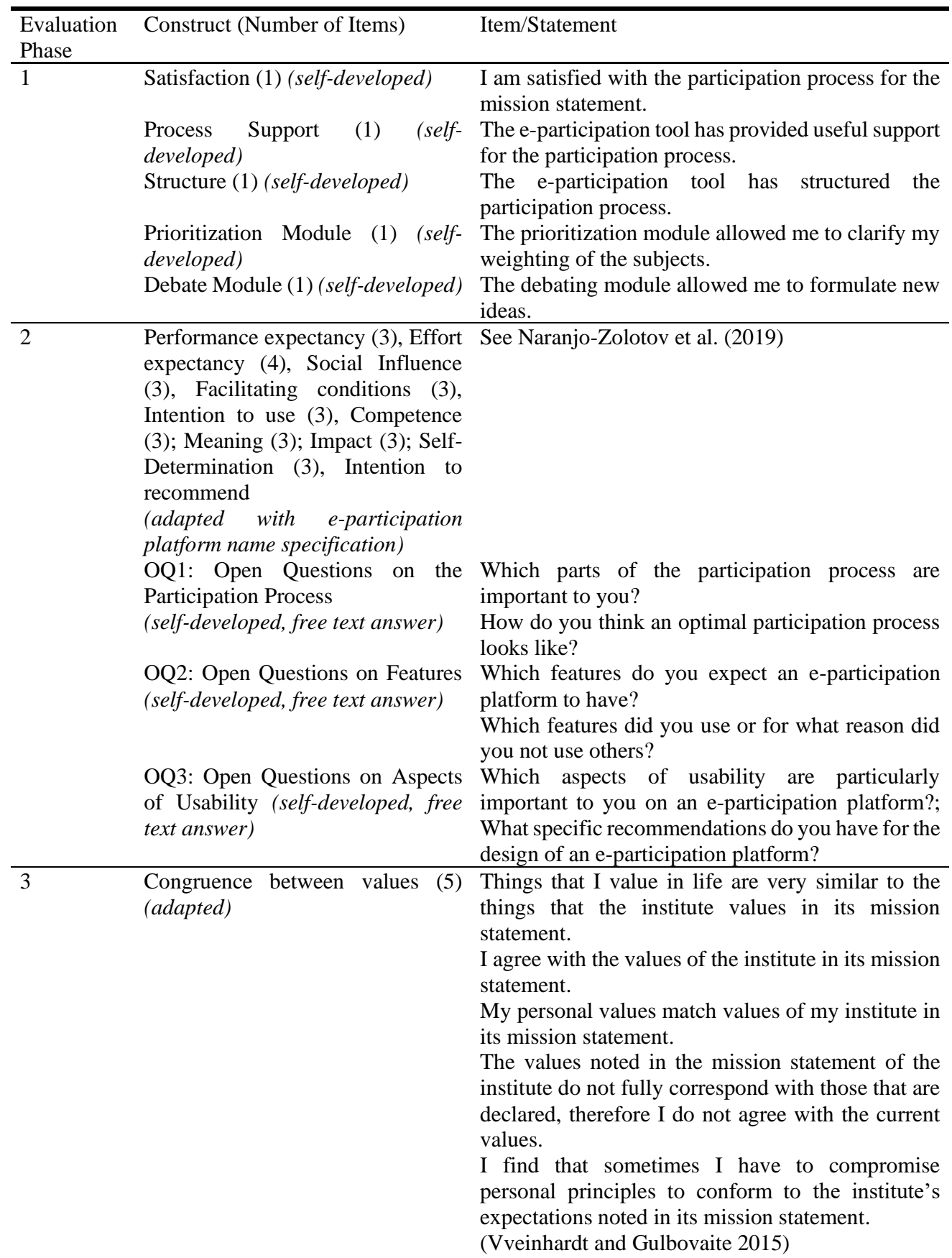


IADIS International Journal on Computer Science and Information Systems

$\begin{aligned} & \text { Participation Influence (5) (self- } \begin{array}{l}\text { It was important to me that the mission statement } \\ \text { developed) } \\ \text { was developed in a participatory manner. }\end{array} \\ & \text { The participatory development process had an } \\ & \text { impact on my value congruence with the mission } \\ & \text { statement. } \\ & \text { The participatory nature of the development } \\ & \text { process improved my personal identification with } \\ & \text { the mission statement. } \\ & \text { My participation in the development process had no } \\ & \text { influence on my congruence with the mission } \\ & \text { statement. } \\ & \text { I would have identified more poorly with a } \\ & \text { non-participative developed mission statement. }\end{aligned}$
$\begin{array}{ll}\text { OQ4: Open Question on Effects on } & \text { What does the mission statement mean to you in } \\ \text { Daily Life (self-developed, free text your daily work? } \\ \text { answer) }\end{array}$

\section{RESULTS}

With this paper, we aim at revealing promises and challenges of the use of e-participation for mission statement development. For this, we build upon the results of the three evaluation phases. Given that we only evaluated the platform and method by means of one organization and a small sample size (valuation phase one: $\mathrm{N}=10$; evaluation phase two: $\mathrm{N}=21$, evaluation phase three: $\mathrm{N}=27$ ), we do not strive for generalizability of the evaluation results. However, we believe that the evaluation can identify some trends and thereby provides avenues for further research. Taking the evaluation results into account, we have to keep in mind that the assessment of the usability of an e-participation platform varies depending on the different stakeholders involved in the use of the tool (Axelsson et al. 2013). In particular, stakeholder groups with lower urgency for the introduction of a new platform may be more reluctant to accept it, while the beneficiaries tend to be more optimistic and develop higher acceptance intentions.

\subsection{Evaluation Phase One: Evaluation During Participation}

The first evaluation was conducted during the participation process and gave a rather positive impression although it has already shown mixed results in the sense that it became clear that there was no distinct endorsement for the platform, which became even more visible in the second evaluation phase. The overall satisfaction with the process was rated above average, given that the middle point of the Likert scale is $4(\mathrm{M}=4.30, \mathrm{SD}=1.19)$. Asking about the specific modules, they seem to have fulfilled their purpose: Participants mostly agreed that they could formulate new ideas $(\mathrm{M}=5.10, \mathrm{SD}=1.37)$ using the module for debate and that they could clarify their weighting of the subjects using the prioritization module $(\mathrm{M}=4.50, \mathrm{SD}=1.56)$. Although a majority agreed that the platform was useful to support the process $(\mathrm{M}=4.70, \mathrm{SD}=0.90)$, only some participants believed that the platform is structured logically $(\mathrm{M}=3.60, \mathrm{SD}=1.28)$. 


\subsection{Evaluation Phase Two: UTAUT-Based Platform Assessment}

In light of the partly inconclusive results of the first evaluation, we wanted to get a better understanding of the problems the participants see with the e-participation platform. Therefore, we used the constructs of the UTAUT-model based framework of Naranjo-Zolotov et al. (2019) (Table 2) to evaluate the e-participation platform. Due to the sample size, we stick to report descriptive results for the variables of interest, since the sample size requirements for a sound structural equation modelling analysis (in accordance with Naranjo-Zolotov et al. (2019) for testing their theoretical model in our context) are not met. Furthermore, we asked some open questions to get feedback that is specifically tailored on the participation process, the usability of the platform as well as its features, and how those aspects might be improved. When we interpret the duality of the results of the second evaluation, we have to keep the technical proficiency of the participants in mind - all are associated with an Information Systems institute. The facilitating conditions like the knowledge and resources necessary to use the platform were evaluated as strongly positive $(\mathrm{M}=6.39, \mathrm{SD}=0.82$; please note: Due to an insufficient Cronbach's alpha value (.64), the item "the platform is compatible with other technologies I use" was removed before aggregating the single item's values to one measure; after removing the item, the construct's Cronbach's alpha value (.77) met the commonly applied threshold value of .7). The effort expectancy $(\mathrm{M}=5.11, \mathrm{SD}=1.45)$, which captures the ease for the users in learning and understanding how to use and interact with the system, was evaluated positively as well. Furthermore, the users were confident about their abilities and skills to use the e-participation platform, shown by the positive competence outcome ( $M=5.70, S D=1.16)$. Only slightly above average was the self-determination $(\mathrm{M}=4.37, \mathrm{SD}=1.56)$ the users perceived over their platform use. Self-determination measures the autonomy and independence in the usage and since decision-making processes should rely on the freedom of choice, we would have expected a better outcome. Both constructs, meaning $(\mathrm{M}=4.43, \mathrm{SD}=1.53)$ and social influence $(\mathrm{M}=4.00, \mathrm{SD}=1.36)$, revealed more details about the process itself: The participants apparently saw the project's meaningfulness (the value for the using person) above average. That being said, a social influence (the extent to which a person perceives that others believe that he or she should use the system) outcome on the middle point of the scale showed no clear opinion if the people with an influence on their behavior would like them to use the platform.

In contrast to the prior constructs, the following showed rather negative results: With the construct performance expectancy $(\mathrm{M}=2.77, \mathrm{SD}=1.43)$, the usefulness of the platform in daily life, the ability to accomplish things more quickly, and the increase of productivity through the tool is captured. The remarkably low results emphasize that the participants did not see the e-participation platform as a valuable addition to their set of digital tools. In this regard, it could be argued that a mission statement development process is not an everyday activity and, thus, limitations in the user experience are tolerable. However, in the same vein, the results for the intention to use $(\mathrm{M}=2.19, \mathrm{SD}=1.11)$ indicate serious concerns. The results revealed hesitancy towards using the e-participation platform besides the presented use case. A below average impact (keeping the users informed about the effects of their participation) result $(\mathrm{M}=3.44$, $\mathrm{SD}=1.26$ ) showed, that the participants did not see the platform as a strong means to influence what happens in their environment. However, it has to be stated, that interpreting this result is complex, since it could be seen positively that in a process that has been envisioned as democratic, the participants have not overestimated the personal impact. In line with the low satisfaction with the used e-participation platform, the value for intention to recommend the platform to others is rather low $(\mathrm{M}=3.62, \mathrm{SD}=1.94)$. The results for the individual constructs are summarized in Table 3. 
IADIS International Journal on Computer Science and Information Systems

Table 3. Descriptive Statistics

\begin{tabular}{lcccc}
\hline Construct & Mean (M) & Median & $\begin{array}{c}\text { Standard Deviation } \\
(\mathrm{SD})\end{array}$ & Cronbach's Alpha \\
\hline Satisfaction $(\mathrm{N}=10)$ & 4.30 & 4.50 & 1.10 & - \\
Process support $(\mathrm{N}=10)$ & 4.70 & 5.00 & 0.90 & - \\
Structure $(\mathrm{N}=10)$ & 3.60 & 3.00 & 1.28 & - \\
Prioritization module $(\mathrm{N}=10)$ & 5.10 & 5.00 & 1.37 & - \\
Debate module $(\mathrm{N}=10)$ & 4.50 & 5.00 & 1.56 & 0.89 \\
Performance expectancy (N=2 & 2.77 & 2.33 & 1.43 & 0.86 \\
Effort expectancy $(\mathrm{N}=21)$ & 5.11 & 5.00 & 1.45 & 0.86 \\
Social influence $(\mathrm{N}=21)$ & 4.00 & 4.00 & 1.36 & 0.77 \\
Facilitating conditions $(\mathrm{N}=21)$ & 6.39 & 6.50 & 0.82 & (third item \\
& & & & dropped) \\
& & & & 0.86 \\
Intention to use $(\mathrm{N}=21)$ & 2.19 & 2.00 & 1.11 & 0.94 \\
Competence $(\mathrm{N}=21)$ & 5.70 & 5.66 & 1.16 & 0.93 \\
Meaning (N=21) & 4.43 & 4.66 & 1.53 & 0.90 \\
Impact (N=21) & 3.44 & 3.33 & 1.26 & 0.90 \\
Self-determination $(\mathrm{N}=21)$ & 4.37 & 4.00 & 1.56 & 0.97 \\
Intention to recommend (N=21 & 3.62 & 3.33 & 1.94 &
\end{tabular}

For analyzing the open questions, we followed the qualitative research approach of a structured content analysis (Gläser and Laudel 2010). Following our analysis, we were able to sort the answers into three categories: participation process, platform features and platform usability. In the following, we will introduce several summarized ideas that were mentioned in the open questions section. For each question, every participant could express several ideas; therefore, the percentages in the following paragraphs of the evaluation represent the share of participants who expressed a common idea. Consequently, the percentages are not mutually exclusive and always reflect the amount of participants expressing a similar idea in relation to the sum of participants.

Participation process: The responses to the open questions (OQ1) on the participation process showed that the participants valued the general participative character of the process as well its realization on the e-participation platform. $20.69 \%$ of the participants mentioned the online voting positively, $17.24 \%$ the online debates, while only $6.90 \%$ mentioned explicitly that they liked the possibility to comment. Some participants (13.79\%) positively mentioned the collaborative teamwork. However, others stated explicitly aspects of the offline workshop $(13.79 \%)$ and that they liked the combination of online and offline participation $(10.34 \%)$ and thereby showing, that some respondents truly valued the offline components of the presented participatory process and that they partly missed personal interactions. In contrast, $13.79 \%$ appreciated the anonymity of the e-participation process and saw it as strength for inner-organizational participation. Only 3.44\% of the contributions highlighted the moderators' role.

Platform features: Regarding the desired features (OQ2) of an e-participation platform supporting a mission statement development, users showed interest in the following functionalities: voting (30.95\%), having surveys (16.67\%), discussion forums (11.90\%), commenting $(9.53 \%)$, submitting own contributions $(7.14 \%)$, and text editing $(7.14 \%)$. Other desired aspects were personalized filters and sorting options (7.14\%), better visualization features to illustrate statistics and user behavior on the platform $(4.76 \%)$, process tracking $(2.38 \%)$, and more dynamic moderation features $(2.38 \%)$. Since many of those suggestions were 


\section{MISSION STATEMENT ACCOMPLISHED: PROMISES AND CHALLENGES IN USING}

E-PARTICIPATION FOR MISSION STATEMENT DEVELOPMENT

not or only partly supported by the used e-participation platform, we consider that the mentioned features can present beneficial extensions for the platforms (or comparable platforms) in future.

Some participants stated important reasons for their hesitancy towards commenting and submitting own contributions, such as doubting the influence of the individual participation, being demoralized by a lack of feedback from other users, or fearing a lack of anonymity. In terms of their intrinsic motivation to participate, having no strong opinion on some topics or a feeling that there is already sufficient representation of one's own opinions also led towards not participating.

Platform usability: Relying on UTAUT-based constructs for platform evaluation, we have already given a broader impression on the tool's usability. With the open questions on the usability (OQ3), we therefore aimed at identifying requirements for an e-participation platform for mission statement development. The participants value simplicity (19.44\%), a clear structure $(16.67 \%)$, interactivity $(13.89 \%)$, and intuitiveness $(11.11 \%)$. Other minor aspects, which each account for $8.3 \%$ of the contributions are transparency, efficacy, and the possibility to participate quickly. Specific suggestions for a better e-participation design addressed mostly a lack of transparent navigation and aimed for a flatter and clearer website hierarchy. Further thought-provoking suggestions were: using aspects of gamification for better user involvement, using icons to make the functions of certain modules directly visible, better tagging features, or even automated clustering of ideas, developing a mobile application allowing to use the e-participation platform more properly also on mobile devices, and possibilities to switch between anonymous and non-anonymous user interaction.

\subsection{Evaluation Phase Three: Satisfaction with the Outcome of Participation Process}

In contrast to the critical assessment of the platform, the third evaluation, measuring value congruence and participation influence, showed that the qualitative outcome of the process was rated very satisfactory. The items within these two constructs contained several positively and negatively framed questions. With regard to value congruence, the five different framings of the question whether their personal values were reflected in the mission statement, the participants overwhelmingly agreed on the suitability (average positive framing: $\mathrm{M}=5.67, \mathrm{SD}=0.74$; average negative framing: $\mathrm{M}=2.52, \mathrm{SD}=1.26$ ). In this context, $92.63 \%$ of the participants stated that they concurred with the values formulated in the mission statement (rating five or higher). Due to the lack of a comparative value of a mission statement developed without employee participation, the participants themselves assessed the influence and value of the participatory element. The evaluation of the five different framings of the question whether the participatory element of the process had positively influenced their identification with the mission statement shows a clear tendency that e-participation improved the participation influence among the participants (average positive framing: $\mathrm{M}=4.94, \mathrm{SD}=1.72$, negative framing: $\mathrm{M}=3.15, \mathrm{SD}=1.51$ ). $74.07 \%$ of the participants rated the participatory element in the process as important. 
IADIS International Journal on Computer Science and Information Systems

Table 4. Descriptive Statistics. Note: Pf accounts for positively framed questions, Nf accounting for negatively framed questions

\begin{tabular}{lcccc}
\hline Construct & & Mean (M) & Median & Standard Deviation (SD) \\
\hline Value congruence & VC Pf (1) & 5.44 & 6 & 0.79 \\
$(\mathrm{~N}=27)$ & VC Pf (2) & 5.81 & 6 & 0.72 \\
& VC Pf (3) & 5.74 & 6 & 0.70 \\
& VC Nf (1) & 2.89 & 2 & 1.29 \\
Participation influenc IP Pf (1) & 2.15 & 2 & 1.24 \\
$(\mathrm{~N}=27)$ & IP Pf (2) & 5.63 & 6 & 1.72 \\
& IP Pf (3) & 4.04 & 4 & 1.65 \\
& IP Pf (4) & 4.76 & 5 & 1.60 \\
& IP Nf (1) & 3.15 & 6 & 1.89 \\
& & 3 & 1.51
\end{tabular}

With the open question "What does the mission statement mean to you in your daily work?" we wanted to get an impression on the influence of the mission statement on the everyday working life of the employees, weeks after it had been discussed. The evaluation of the open question allowed us to differentiate between participants $(\mathrm{N}=27)$ to whom the mission statement was rather less important in the daily work (48\%) and those who valued it (52\%) either as a source of orientation for values and norms or as a concrete recommendation in interaction with their colleagues.

Table 5. Selected Participant Quotes relating to OQ4

\begin{tabular}{|c|c|}
\hline Answer Category & Quotes \\
\hline $\begin{array}{l}\text { The mission } \\
\text { statement was not } \\
\text { very present in my } \\
\text { daily business }\end{array}$ & $\begin{array}{c}\text { "I thought it was quite good at the time and corresponded to my understanding } \\
\text { of our cooperation. But the fact that it now officially exists changes little in } \\
\text { the everyday life." } \\
\text { "It is good that we have it to refer to it - but actually I rarely think about it } \\
\text { and it does not affect my work that much." }\end{array}$ \\
\hline $\begin{array}{l}\text { The mission } \\
\text { statement serves as } \\
\text { passive orientation } \\
\text { for values and norms } \\
\text { for me }\end{array}$ & $\begin{array}{l}\text { "They are "higher goals / values" that I find good and share." } \\
\text { "[To me it gives] orientation for the work culture at the chair", }\end{array}$ \\
\hline $\begin{array}{lr}\begin{array}{l}\text { The } \\
\text { statement } \\
\text { concrete }\end{array} & \text { offers } \\
\end{array}$ & $\begin{array}{c}\text { "For me, the mission statement means better cooperation in meetings with } \\
\text { many participants." }\end{array}$ \\
\hline $\begin{array}{l}\text { recommendations } \\
\text { when interacting with } \\
\text { my colleagues }\end{array}$ & $\begin{array}{c}\text { "It helps as a communication medium/anchor for conversations with } \\
\text { employees." }\end{array}$ \\
\hline
\end{tabular}

\section{DISCUSSION, FUTURE RESEARCH, AND CONCLUSION}

Based on the general trend towards digitizing the workplace - especially sparked by the Covid-19 pandemic - we argued that there is a strong case for using e-participation for mission statement development. Within this paper, we demonstrated promises and challenges of using e-participation for mission statement development, and our contribution lies in presenting a 


\section{MISSION STATEMENT ACCOMPLISHED: PROMISES AND CHALLENGES IN USING}

E-PARTICIPATION FOR MISSION STATEMENT DEVELOPMENT

nominal group process, consisting of eight activities, for their deployment. In our evaluation, we investigated the acceptance of the process, the mission statement itself and assessed the ICT tool regarding its features and usability. The study, which consisted of three evaluation phases, showed an interest in using e-participation platforms for this purpose, but the challenge seems to lie in finding the right platform or respectively in refining the existing ones. The evaluation results allowed us to draw first conclusions about designing and implementing a mission statement process with e-participation. The results of the evaluation phase one and the open questions showed that the suggested modules (debate and prioritization) were accepted and supported by most participants. We could verify the results of mission statement research (Desmidt and Prinzie 2009) emphasizing that participants value opportunities to participate. Especially voting mechanism seemed to be an attractive feature of e-participation. The respondents also liked more time-consuming activities such as discussions, text editing, or commenting. Therefore, we do not see any need to adapt the suggested nominal group process and do see possibilities for other organizations to reuse it. The users made us aware of the merits of hybrid formats, which connect off- and online activities, since both elements seem important to satisfy various stakeholders and create a certain team spirit.

Moreover, the results of evaluation phase two showed, that the used platform overall did not satisfy the participants. Although users were convinced that they had the necessary resources, abilities, and skills to use the platform, they had a low intention to use and recommend the system. Future efforts to develop or select an appropriate platform for supporting a participative online mission statement process should therefore strongly focus on usability aspects, e.g., those suggested in our results section, in which we showed that platform should be simple and should follow a clear structure allowing a fast and intuitive navigation. State-of-the-art possibilities for a more entertaining user experience and better user interaction should be integrated to provide incentives for using the platform.

The results from evaluation phase three indicate, however, that these additional efforts in applying e-participation and developing or improving suitable platforms, pay off eventually as the participatory element was not only valued by participants, but also improved their identification with the mission statement. This leads to a majority of participants utilizing the mission statement even in their day-to-day work, which we argue to be a great success in creating a unifying team spirit and a shared mission.

In this paper, we made the case for the combination of mission statement development with e-participation. Since the used and tested e-participation platform did not met the requirements, for future research, it would be interesting to explore how other platforms master the described process. Although we primarily focused on mission statement development, we see further potential to use the presented process for other e-participation initiatives, which aim for the same project objective, namely a decision-making supplement. We believe that combining e-participation with mission statement development would be an exciting artifact to be developed within a design science research project (Hevner et al. 2004). Thereby, meta-requirements, design principles and a design theory for an e-participation platform for mission statement creation could be investigated. Addressing the named challenges and aiming to reach the promises in future research, we are interested to see, how our nominal group process for participatory mission statement development will be adopted and refined. 
IADIS International Journal on Computer Science and Information Systems

\section{REFERENCES}

Adamczyk, S. et al., 2012. Innovation Contests: A Review, Classification and Outlook. Creativity and Innovation Management, Vol. 21, No. 4, pp. 335-360.

Alegre, I. et al., 2018. The real mission of the mission statement: A systematic review of the literature. Journal of Management \& Organization. Cambridge University Press, 24(4), pp. 456-473.

Åström, J. et al., 2012. Understanding the Rise of E-participation in Non-Democracies: Domestic and International Factors. Government Information Quarterly, Vol. 29, No. 2, pp. 142-150.

Axelsson, K. et al., 2013. Public E-Services for Agency Efficiency and Citizen Benefit - Findings from a Stakeholder Centered Analysis. Government Information Quarterly, Vol. 30, No. 1, pp. 10-22.

Baetz, M. C. and Bart C. K., 1996. Developing mission statements which work. Long Range Planning, Vol. 29, No. 4, pp. 526-533.

Blair-Loy, M. et al., 2011. Exploring the Relationship between Mission Statements and Work-Life Practices in Organizations. Organization Studies, Vol. 32, No. 3, pp. 427-450.

Bonacini, L. et al., 2021. Working from Home and Income Inequality: Risks of a 'New Normal' with COVID-19. In: Journal of Population Economics, No. 34, pp. 303-360.

Campbell, A. and Yeung, S., 1991. Creating a sense of mission. Long Range Planning, Vol. 24, No. 4, pp. $10-20$.

Cochran, D. S. et al., 2008. A Framework for Developing an Effective Mission Statement. Journal of Business Strategies, Vol. 25, No. 2, p. 27.

Desmidt, S. and Prinzie, A. A., 2009. The Effectiveness of Mission Statements: An Explorative Analysis from a Communication Perspective. Academy of Management Proceedings, Vol. 2009, No. 1, pp. 1-6.

Deutsche Welle, 2020. German labor minister calls for right to work from home. Available online under https://p.dw.com/p/3bRdG

Ekstrom, M. et al., 2020. Commentary: Digitization, climate change, and the potential for online workshops. New Media \& Society, Vol. 22 (2), pp. 378-383.

Fegert, J., et al., 2020. Combining e-participation with Augmented and Virtual Reality: Insights from a Design Science Research Project. Proceedings of the International Conference on Information Systems (ICIS 2020). Hyderabad, India.

Gläser, J. and Laudel, G., 2010. Experteninterviews und qualitative Inhaltsanalyse: als Instrumente rekonstruierender Untersuchungen. VS Verlag für Sozialwissenschaften, Wiesbaden.

Grudin, J., 1994. Computer-supported cooperative work: history and focus. Computer, Vol. 27. No. 5, pp. 19-26.

Grönlund, Å., 2009. ICT Is Not Participation Is Not Democracy - Eparticipation Development Models Revisited. International Conference on Electronic Participation, Linz, Austria, pp. 12-23.

Hevner, A. R. et al., 2004. Design Science in Information Systems Research. MIS Quarterly, Vol. 28. No. 1, pp. 75-105.

Kalampokis, E. et al., 2008. A Domain Model for EParticipation. Third International Conference on Internet and Web Applications and Services, Athens, Greece, pp. 25-30.

King, W. R., 1978. Strategic Planning and Policy. Van Nostrand Reinhold, New York, USA.

Klemm, M. et al., 1991. Mission Statements: Selling Corporate Values to Employees. Long Range Planning, Vol. 24, No. 3, pp. 73-78.

Klöwer, M. et al., 2020. An analysis of ways to decarbonize conference travel after COVID-19. Nature, Vol. 583, pp. 356-359.

Lindner R. and Aichholzer G., 2020. E-Democracy: Conceptual Foundations and Recent Trends. In: Hennen L., van Keulen I., Korthagen I., Aichholzer G., Lindner R., Nielsen R. (eds) European E-Democracy in Practice. Studies in Digital Politics and Governance. Springer, Cham. 


\section{MISSION STATEMENT ACCOMPLISHED: PROMISES AND CHALLENGES IN USING E-PARTICIPATION FOR MISSION STATEMENT DEVELOPMENT}

Leitner, M., 2018. Digitale Bürgerbeteiligung: Forschung und Praxis, Chancen und Herausforderungen der elektronischen Partizipation. Springer-Verlag, Berlin, Deutschland.

Macintosh, A., 2004. Characterizing E-participation in Policy-Making. Proceedings of the 37th Annual Hawaii International Conference on System Sciences, Washington DC, USA, pp. 1-10.

Naranjo-Zolotov, M. et al., 2019. Citizens' Intention to Use and Recommend e-participation: Drawing upon UTAUT and Citizen Empowerment. Information Technology \& People, Vol. 32, No. 2, pp. 364-386.

Niemeyer, C. et al., 2016. Participatory Crowdfunding: An approach towards engaging employees and citizens in institutional budgeting decisions. Proceedings of the 49th Annual Hawaii International Conference on System Science, Kauai, Hawaii, pp. 2800-2808.

Pearce, J. A. and David, F., 1987. Corporate Mission Statements: The Bottom Line. Academy of Management Perspectives, Vol. 1, No. 2, pp. 109-115.

Phang, C. W. and Kankanhalli, A., 2008. A Framework of ICT Exploitation for E-participation Initiatives. Communications of the ACM, Vol. 51, No. 12, pp. 128-132.

Sanford, C. and Rose, J., 2007. Characterizing eParticipation. International Journal of Information Management, Vol. 27, No. 6, pp. 406-421.

Sattari, S. et al., 2011. How readable are mission statements? An exploratory study. Corporate Communications: An International Journal, Vol. 16, No. 4, pp. 282-292.

Scherer, S. and Wimmer, M. A., 2011. Reference Framework for E-participation Projects. International Conference on Electronic Participation, Delf, The Netherlands, pp. 145-156.

Thiel, S.-K. et al., 2018. Nutzerorientierte Gestaltung von interaktiver E-Partizipation. Digitale Bürgerbeteiligung: Forschung und Praxis - Chancen und Herausforderungen der elektronischen Partizipation, Springer Fachmedien, Wiesbaden, Germany, pp. 127-161.

United Nations, General Assembly, 2015. Resolution adopted by the General Assembly on 25 September 2015: Transforming our world: the 2030 Agenda for Sustainable Development. Retrieved from https://sustainabledevelopment.un.org/post2015/summit

United Nations, Department of Economic and Social Affairs, and Population Division, 2019. World Urbanization Prospects: The 2018 Revision.

United Nations, 2020a. Embracing Digital Government during the Pandemic and Beyond. Retrieved from https://www.un.org/development/desa/dpad/publication/un-desa-policy-brief-61-covid-19embracing-digital-government-during-the-pandemic-and-beyond/.

United Nations, 2020b. E-Government Survey 2020: Digital Government in the Decade of Action for Sustainable Development. Retrieved from https://www.un.org/development/desa/publications/publication/2020-united-nations-e-governmentsurvey

Venkatesh, V. et al., 2003. User Acceptance of Information Technology: Toward a Unified View. MIS Quarterly, Vol. 27, No. 3, pp. 425-478.

Vveinhardt, J. and Gulbovaite, E. (2015). Expert evaluation of diagnostic instrument for personal and organizational value congruence Journal of Business Ethics, Vol. 136, No. 3, pp. 481-501.

Wagenknecht, T. et al., 2017a. Ideate. Collaborate. Repeat. A Research Agenda for Idea Generation, Collaboration and Evaluation in Open Innovation. 13th International Conference on Wirtschaftsinformatik, St.Gallen, Switzerland, pp. 12-15.

Wagenknecht, T. et al., 2017b. Towards a Design Theory of Computer-Supported Organizational Participation. Journal of Enterprise Information Management, Vol. 30, No. 1, pp. 188-202.

Wagenknecht, T. et al., 2017c. Crowdsourcing in a Public Organization: Transformation and Culture Americas Conference on Information Systems 2017 Proceedings, Boston, USA, pp. 1-10. 